\title{
Microbiological components in mainstream and sidestream cigarette smoke
}

\author{
Lennart Larsson ${ }^{1 *}$, Christina Pehrson ${ }^{1}$, Tenzin Dechen ${ }^{2}$ and Mardi Crane-Godreau ${ }^{2}$
}

\begin{abstract}
Background: Research has shown that tobacco smoke contains substances of microbiological origin such as ergosterol (a fungal membrane lipid) and lipopolysaccharide (LPS) (in the outer membrane of Gram-negative bacteria). The aim of the present study was to compare the amounts of ergosterol and LPS in the tobacco and mainstream (MS) and sidestream (SS) smoke of some popular US cigarettes.

Methods: We measured LPS 3-hydroxy fatty acids and fungal biomass biomarker ergosterol in the tobacco and smoke from cigarettes of 11 popular brands purchased in the US. University of Kentucky reference cigarettes were also included for comparison.

Results: The cigarette tobacco of the different brands contained 6.88-16.17 (mean 10.64) pmol LPS and 8.27-21.00 (mean 14.05) $\mathrm{ng}$ ergosterol/mg. There was a direct correlation between the amounts of ergosterol and LPS in cigarette tobacco and in MS smoke collected using continuous suction; the MS smoke contained 3.65-8.23\% (ergosterol) and $10.02-20.13 \%$ (LPS) of the amounts in the tobacco. Corresponding percentages were $0.30-0.82 \%$ (ergosterol) and $0.42-1.10 \%$ (LPS) for SS smoke collected without any ongoing suction, and $2.18 \%$ and $2.56 \%$ for MS smoke collected from eight two-second puffs.
\end{abstract}

Conclusions: Tobacco smoke is a bioaerosol likely to contain a wide range of potentially harmful bacterial and fungal components.

Keywords: Lipopolysaccharide, Ergosterol, Tobacco, Cigarette smoke

\section{Background}

Tobacco smoke contains several thousands of chemicals and most of them are formed during the burning of the tobacco [1]. Other chemicals in the smoke may be present in the tobacco itself, surviving the combustion during the smoking. Examples are compounds from microorganisms that naturally colonize tobacco leaves. That tobacco is rich in both bacteria and in fungi has been known for decades [2], but it was not until modern molecular biology methods became available, such as $16 \mathrm{~S}$ rRNA sequence analysis, that a rich diversity of the microbes in tobacco was revealed. Thus, a large number of species of both Gram-positive and Gram-negative bacteria and of molds have been identified [3,4]. Hasday et al. [5] found that cigarette smoke contains biologically active endotoxin; this was

\footnotetext{
* Correspondence: Lennart. Larsson@med.lu.se

'Dept of Laboratory Medicine, Lund University, Lund, Sweden

Full list of author information is available at the end of the article
}

the first time that a specific group of bacterial toxins were proven to be present in tobacco smoke. Larsson et al. [6,7] used gas chromatography-tandem mass spectrometry (GC-MSMS) to demonstrate the presence of lipopolysaccharide (LPS), i.e. the endotoxin molecule of the outer membrane in all Gram-negative bacteria, in smoke. The LPS concentrations in indoor air were directly proportional to the number of cigarettes smoked during a given time interval [8]. Ergosterol, a fungal membrane lipid, was also identified, both in the tobacco and the smoke. A positive relationship was found between the amounts of LPS and ergosterol in the tobacco of a studied cigarette and the amounts of these substances in mainstream smoke [7]. The concentrations of the microbiological compounds in the tobacco of some local brands of Vietnamese and Chinese cigarettes were much lower than in the tobacco of international brands of cigarettes purchased in different European and Asian countries [7]. The reason for this difference is unknown;

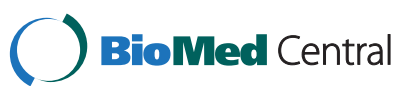

(c) 2012 Larsson et al.; licensee BioMed Central Ltd. This is an Open Access article distributed under the terms of the Creative Commons Attribution License (http://creativecommons.org/licenses/by/2.0), which permits unrestricted use, distribution, and reproduction in any medium, provided the original work is properly cited. 
however, both pesticides and fungicides are known to be common on tobacco plantations.

The studies published so far on ergosterol and LPS in tobacco smoke have utilized a home-made sampling device for collecting mainstream (MS) smoke; sidestream (SS) smoke has to date not been analyzed for these compounds. The aim of the present study was to measure LPS and ergosterol in the tobacco as well as in MS and SS smoke of several brands of popular cigarettes purchased in the US. LPS was measured by determining the number of moles of 3-hydroxy fatty acids (3-OH FAs) of 10-18 carbon chain lengths [6]. The smoke samples were generated by adapting a Teague TE-10, a standard research cigarette smoke generating device.

\section{Methods}

\section{Cigarette tobacco and smoke samples}

Packs of cigarettes of 11 US brands (Camel Turkish Royal, Marlboro Red, Marlboro Light, Marlboro Menthol, Pall Mall, Winston, Newport Menthol, Kool, Parliament Lights, Basic Full Flavor, and Liggett Select Full Flavor) were purchased at a store in Boston MA and kept in a freezer $(-20 \mathrm{C})$ until use. University of Kentucky 3R4F research cigarettes were used for reference.

Tobacco from one cigarette of each of the 11 brands plus one University of Kentucky reference cigarette was studied. In addition, samples of MS and SS smoke of cigarettes of six brands (Camel Turkish Royal, Pall Mall, Newport Menthol, Kool, Parliament Lights, and Liggett Select Full Flavor), plus University of Kentucky reference cigarettes, were used. The smoke was generated using a smoking machine and collected on Pall Life Sciences, PallFlex Membrane Filters (PMMF, EmFab TX40H120WW). In each series of experiments a filter that had not been exposed to the smoke was used as a negative control.

The smoking apparatus used was a Teague Enterprises TE-10 smoking system equipped with two exposure chambers $[9,10]$. The smoking device is microprocessor controlled and produces both MS and SS smoke, or SS smoke alone. Smoke is drawn from the combustion chamber into a mixing chamber and then into exposure chambers. Valves control airflow and permit purging smoke from within the mixing and exposure chambers into dedicated ducting that conducts all purged smoke outside the building. In the SS smoke experiments all smoke was directed into the upper chamber. In the MS smoke experiments, the smoke was drawn through a lit cigarette into a Buchner flask. Although one cigarette burns out in less than one min, 6 min suction was used to assure that the flask was fully evacuated of smoke. SS smoke was collected from lit cigarettes without any ongoing suction. The suction on the (larger) chamber was run for 12 min followed by a "blow out" to prevent any remaining smoke in the collection chamber.

In three experiments smoke from lit Marlboro light cigarettes was collected using 8 puffs ( 2 seconds/puff) per cigarette in order to estimate the smoke concentrations of LPS and ergosterol under realistic smoking conditions. Only MS smoke, from one cigarette/experiment, was collected in a flask and then drawn into the filter during $6 \mathrm{~min}$.

\section{Sample preparation and analysis}

The tobacco samples (of one whole cigarette each) were weighed and, just as the PMMF filter samples, transferred to glass test tubes equipped with Teflon-lined screw caps. One set of samples was prepared for analysis by GC-MSMS of 3-OH FAs following acid methanolysis and silylation and a separate set of samples was prepared for analysis of ergosterol following alkaline hydrolysis and silylation, as described [11]. The entire methanolysate and hydrolysate samples of the filters and a 1/100th fraction of the methanolysate and hydrolysate samples of the tobacco were subjected to the subsequent preparatory steps before being analysed. The amounts of LPS were calculated by summarizing the number of moles of the 3-OH FAs and dividing by four, assuming that one mole of LPS contains four moles of 3-OH FAs [11].

\section{Statistical analysis}

The Spearman and Pearson tests were used for studying correlations between the amounts of LPS and ergosterol in the cigarette tobacco with the amounts in MS and SS smoke.

\section{Results}

\section{LPS and ergosterol in cigarette tobacco}

The cigarettes contained each approximately $700 \mathrm{mg}$ of tobacco. One $\mathrm{mg}$ of tobacco contained 6.88 - 16.17 (mean 10.64, SD 1.91) pmol LPS and 8.27-21.0 (mean 14.05, SD 4.25) ng ergosterol (Table 1).

\section{LPS and ergosterol in tobacco smoke}

Cigarettes of six brands containing relatively high and relatively low or medium concentrations of the microbiological compounds, respectively, plus one University of Kentucky cigarette, were selected for analysis of MS and SS smoke. MS smoke from one cigarette produced by continuous suction contained 384-725 ng ergosterol and 823-1504 pmol LPS corresponding to $3.65-8.23 \%$ and $10.02-20.13 \%$, respectively, of the amounts in the tobacco per cigarette of a given brand. By comparison, SS smoke collected from one cigarette without any ongoing suction contained $17-78$ ng ergosterol and 41-71 pmol LPS corresponding to $0.30-0.82 \%$ and $0.42-1.10 \%$, 
Table 1 LPS and ergosterol in cigarette tobacco $(\mathrm{N}=1)$

\begin{tabular}{lcc}
\hline Cigarette & Erg $\mathbf{n g} / \mathbf{m g}$ & LPS $\mathbf{~ p m o l} / \mathbf{m g}$ \\
\hline Camel Turkish Royal & 9.12 & 6.88 \\
Marlboro Red & 15.99 & 10.77 \\
Marlboro Light & 13.65 & 11.15 \\
Marlboro Menthol & 14.70 & 7.84 \\
Pall Mall & 11.29 & 8.83 \\
Winston & 14.04 & 12.83 \\
Newport Menthol & 8.27 & 10.67 \\
Kool & 13.23 & 16.17 \\
Parliament Lights & 15.10 & 13.60 \\
Basic Full Flavor & 13.61 & 11.10 \\
Liggett Select Full Flavor & 18.56 & 8.80 \\
University of Kentucky & 21.00 & 9.00 \\
\hline
\end{tabular}

respectively, of the amounts in the tobacco per cigarette of a given brand (Table 2).

The proportions (percentages) of ergosterol and LPS in the SS smoke samples (collected without any suction) in relation to the MS smoke samples (collected by continuous suction) were in all cases higher for ergosterol (mean 9.47\%) than for LPS (mean 4.73\%) (Table 3).

MS smoke collected by the 8-puff samplings contained on average $0.20 \mathrm{nmol}$ LPS and $218 \mathrm{ng}$ ergosterol per filter, thus $2.56 \%$ and $2.18 \%$, respectively, of the amounts in the cigarette tobacco.

Significant correlations were found between the amounts of LPS in cigarette tobacco and in MS smoke (Spearman, $P=0.016$ ), between ergosterol in cigarette tobacco and MS smoke (Pearson, $P=0.075$ ), and between ergosterol in SS and MS smoke (Pearson, $P=0.015$; Spearman, $P=0.036$ ). The MS samples had been collected using continuous suction and the SS samples had been collected without any suction as described above.

\section{Discussion}

Cigarette smoke contains thousands of chemicals many of which pose a serious health risk. These chemicals may be formed during the burning of the tobacco or may be present in the tobacco itself. Among the latter group of compounds are pesticides and other intact agrochemicals, menthol, flavorants etc. [12]. In recent years it has been demonstrated that also products from microorganisms, such as from bacteria and molds that are ubiquitous in tobacco, may be found in the smoke. Thus, Edinboro et al. [13] identified aflatoxin B1 in SS cigarette smoke by using immunoaffinity column extraction coupled with liquid chromatography/mass spectrometry, and Hasday et al. [5] used the Limulus test to reveal endotoxin in cigarette smoke. The reaction from
Table 2 LPS and ergosterol in the cigarette tobacco and smoke; percentages of LPS and ergosterol in the smoke in relation to the tobacco $(\mathrm{N}=1)$

\begin{tabular}{|c|c|c|c|c|}
\hline Cigarette & Erg ng/cig & $\%$ & LPS pmol/cig & $\%$ \\
\hline \multicolumn{5}{|c|}{ Newport Menthol } \\
\hline Tobacco & 5790 & & 7470 & \\
\hline Sidestream & 17 & 0.30 & 51 & 0.68 \\
\hline Mainstream & 384 & 6.63 & 1504 & 20.13 \\
\hline \multicolumn{5}{|c|}{ Camel Turkish Royal } \\
\hline Tobacco & 6380 & & 4820 & \\
\hline Sidestream & 52 & 0.82 & 51 & 1.06 \\
\hline Mainstream & 525 & 8.23 & 823 & 17.07 \\
\hline \multicolumn{5}{|l|}{ Pall Mall } \\
\hline Tobacco & 7900 & & 6180 & \\
\hline Sidestream & 61 & 0.77 & 68 & 1.10 \\
\hline Mainstream & 457 & 5.78 & 1130 & 18.28 \\
\hline \multicolumn{5}{|l|}{ Kool } \\
\hline Tobacco & 9260 & & 11320 & \\
\hline Sidestream & 40 & 0.43 & 48 & 0.42 \\
\hline Mainstream & 429 & 4.63 & 1134 & 10.02 \\
\hline \multicolumn{5}{|c|}{ Parliament Lights } \\
\hline Tobacco & 10570 & & 9520 & \\
\hline Sidestream & 49 & 0.46 & 41 & 0.43 \\
\hline Mainstream & 488 & 4.62 & 1363 & 14.32 \\
\hline \multicolumn{5}{|c|}{ Liggett Select Full Flavor } \\
\hline Tobacco & 12990 & & 6160 & \\
\hline Sidestream & 41 & 0.32 & 42 & 0.68 \\
\hline Mainstream & 474 & 3.65 & 1044 & 16.95 \\
\hline \multicolumn{5}{|c|}{ University of Kentucky } \\
\hline Tobacco & 15120 & & 6480 & \\
\hline Sidestream & 78 & 0.52 & 71 & 1.10 \\
\hline Mainstream & 725 & 4.79 & 1130 & 17.44 \\
\hline
\end{tabular}

the tobacco industry following the reports in scientific press on the presence of biologically active endotoxin in smoke was reviewed recently [14].

Table 3 Percentage of ergosterol and LPS in sidestream smoke in relation to mainstream smoke

\begin{tabular}{lcc}
\hline Cigarette & Erg \% & LPS \% \\
\hline Newport Menthol & 4.45 & 3.36 \\
Camel Turkish Royal & 9.90 & 6.18 \\
Pall Mall & 13.3 & 6.01 \\
Kool & 9.30 & 4.26 \\
Parliament Lights & 10.00 & 3.00 \\
Liggett Select Full Flavor & 8.57 & 3.99 \\
University of Kentucky & 10.86 & 6.30 \\
\hline
\end{tabular}


Tobacco is an agricultural product and as such contains a myriad of colonising bacteria and fungi. In a previous study we found that the microbial load in a cigarette mostly originates from colonization of the tobacco leaves on the field [7]. Among the microbes found in tobacco, identified by using molecular biological methods and/or microscopy, culturing, and conventional biochemical tests, are for example Acinetobacter, Bacillus, Burkholderia, Clostridium, Klebsiella, Pseudomonas, Serratia, Campylobacter, Enterococcus, Proteus, Staphylococcus, Pantoea, a large range of mesophilic and thermophilic bacteria, and fungi such as for example Aspergillus $[4,7,15,16]$. Bacteria in cigarettes were speculated to be associated with an outbreak of severe pneumonitis in military personnel [17]; bacteria growing on tobacco flakes have been hypothesized as representing a health risk to the smoker [18].

We introduced chemical marker analysis as a new concept for assessing the microbiological contents of tobacco and smoke [6,7]. With this technology the total bacterial biomass in a sample is determined by measuring the amounts of muramic acid, an amino sugar present exclusively in peptidoglycan. Analogously, ergosterol, a specific fungal membrane lipid, is used to quantify fungal biomass, and 3-OH FAs of $10-18$ carbon chain lengths are used to quantify LPS and/or the biomass of Gram-negative bacteria [11]. The amounts of ergosterol and LPS found in the tobacco samples here studied are in general agreement with those found previously in cigarettes of international brands purchased in countries in Europe and Asia. At the same time, these amounts are much higher - up to 20-fold - than in some local cigarettes purchased in China, Korea, and Vietnam [7]. In the present study we did not include muramic acid as an analyte since the amounts in MS and second hand smoke are so low that they are barely detectable [7].

MS smoke collected by eight two-second puffs contained 2-3\% of the amounts of LPS and ergosterol present in the tobacco of one cigarette. These results are in general agreement with those found previously where smoke had been collected by using home-made sampling with a gas-tight syringe [7]. Smoke produced by eight two-second puffs most closely resembles smoke that would occur in a closed space under normal cigarette usage. That is, the number of puffs taken on the cigarette and the length and volume of the puffs are designed to simulate human smoking behaviour.

Use of continuous suction for collecting MS smoke gave a circa 10 times higher smoke/tobacco proportions of LPS and ergosterol as compared with the puffing. The reason for the consistently higher smoke/tobacco proportion of LPS than of ergosterol found in MS smoke is unknown; however, LPS is known to be a heat-stable molecule. The amounts of ergosterol and LPS were much lower - by a factor of approximately 10 (ergosterol) and 20 (LPS), respectively - in SS smoke than in MS smoke. Indeed, microbiological compounds appearing in MS smoke may have been "distilled" through the cigarette during the smoking thus not being exposed to as high temperatures (thereby avoiding extensive thermal degradation) as at the tip of the burning cigarette, resulting in SS smoke. Notably, SS smoke is regarded as being more toxic than MS smoke [19] probably resulting from production of toxic components at very high temperatures.

We showed previously that adding gram-negative bacteria to a cigarette resulting in an 8-fold increase in LPS in the tobacco gave a 4-fold increase in MS smoke. Corresponding increases of ergosterol after fungi had been added to the tobacco were 15-fold (in tobacco) and 9fold (in MS smoke) [7]. Significant correlations between the amounts of LPS and ergosterol in the cigarette tobacco and in MS smoke were also found in the present study. Taken together, these studies strongly indicate that the 3-OH FAs and ergosterol found in smoke stem from bacteria and fungi in the tobacco.

Microorganisms may not be evenly distributed in cigarette tobacco and this may result in difficulties in achieving reproducible analysis results. Analysis of SS smoke from two different University of Kentucky cigarettes revealed 72 and $84 \mathrm{ng}$ ergosterol and 76 and 67 pmoles LPS, respectively (data not shown). Since tobacco from only a single cigarette of each brand was analysed the results of the present study cannot be used to compare different brands. But, the study demonstrates e.g. that a single cigarette of a popular brand, purchased in the US, may contain bacteria and fungi enough to produce $218 \mathrm{ng}$ ergosterol and 0.20 nmoles of LPS at an average smoking behavior, with eight two-second puffs per cigarette. Notably, assuming an average molecular weight of environmental LPS of 8000, 0.2 nmoles of LPS corresponds to $1600 \mathrm{ng}$. We showed previously that smoking 2-12 cigarettes over a 5-h period resulted in 463 times increased concentrations of LPS in indoor air [8]. Cigarette smoke is known to induce inflammation of the lung [20]; further research is required to identify a possible role of the microbiological compounds in smoke in evoking inflammation. It is intriguing that such symptoms in the airways that are common among smokers are also common among nonsmokers with occupational exposure to bioaerosols [21,22].

\section{Conclusions}

Cigarette tobacco contains large amounts of substances of microbiological origin. The compounds focused at in the present study, viz. LPS and ergosterol, should largely be viewed as markers of the plethora of microbial 
components present. We showed that MS smoke produced using a normal smoking behavior may contain more than $2 \%$ of the amounts of ergosterol and LPS that are present in the cigarette tobacco. Public awareness that cigarette smoke exposure entails inhaling toxic and inflammatory microbial compounds may help individuals make informed choices with respect to smoking.

\section{Competing interests}

The authors declare that they have no competing interests.

\section{Authors' contributions}

LL was responsible for the over-all study design and did the main writing. CP made the LPS analyses. MC-G was responsible for production of smoke samples and contributed to the experimental design. TD assisted in the production of the smoke samples. All authors read and approved the final manuscript.

\section{Acknowledgements}

The authors are grateful for the financial support from the Flight Attendant Medical Research Institute (FAMRI).

\section{Author details}

${ }^{1}$ Dept of Laboratory Medicine, Lund University, Lund, Sweden. ${ }^{2}$ Dept of Microbiology \& Immunology, Geisel School of Medicine at Dartmouth, Lebanon, NH, USA.

Received: 8 June 2012 Accepted: 8 August 2012

Published: 16 August 2012

\section{References}

1. Borgerding M, Klus H: Analysis of complex mixtures-cigarette smoke. Exp Toxicology Pathol 2005, 57(1):43-73.

2. Welty RE: Fungi isolated from flue-cured tobacco sold in Southeast United States, 1968-1970. App/ Microbiol 1972, 24(3):518-520.

3. Huang J, Yang J, Duan Y, Gu W, Gong X, Zhe W, Su C, Zhang KQ: Bacterial diversities on unaged and aging flue-cured tobacco leaves estimated by 16S rRNA sequence analysis. Appl Microbiol Biotechnol 2010, 88:553-562.

4. Sapkota AR, Berger S, Vogel TM: Human pathogens abundant in the bacterial metagenome of cigarettes. Environ Health Perspect 2010, 118(3):351-356

5. Hasday JD, Bascom R, Costa JJ, Fitzgerald T, Dubin W: Bacterial endotoxin is an active component of cigarette smoke. Chest 1999, 115:829-835.

6. Larsson L, Szponar B, Pehrson C: Tobacco smoking increases dramatically air concentrations of endotoxin. Indoor Air 2004, 14:421-424.

7. Larsson L, Szponar B, Ridha B, Pehrson C, Dutkiewicz J, Krysinska-Traczyk E, Sitkowska J: Identification of bacterial and fungal components in tobacco and tobacco smoke. Tob Induc Dis 2008, 4(4).

8. Sebastian A, Pehrson C, Larsson L: Elevated concentrations of endotoxin in indoor air due to cigarette smoking. J Environ Monit 2006, 8:519-522.

9. Teague SV, Pinkerton KE, Goldsmith M, Gebremichael A, Chang S, Jenkins RA, Moneyhun JH: Sidestream smoke generation and exposure system for environmental tobacco smoke studies. Inhal Toxicol 1994, 6:79-93.

10. Shang S, Ordway D, Henao-Tamayo M, Bai X, Oberley-Deegan R, Shanley C, Orme IM, Case S, Minor M, Ackart D, Hascall-Dove L, Ovrutsky AR, Kandasamy P, Voelker DR, Lambert C, Freed BM, Iseman MD, Basaraba RJ, Chan ED: Cigarette smoke increases susceptibility to tuberculosis evidence from in vivo and in vitro models. J Infect Dis 2011, 203:1240-1248

11. Sebastian A, Larsson L: Characterisation of the microbial community in indoor environments: a chemical-analytical approach. Appl Environ Microbiol 2003, 69:3103-3109.

12. Pauly JK, Paszkiewicz G: Cigarette smoke, bacteria, mold, microbial toxins, and chronic lung inflammation. J Oncol 2011, 2011:819129.

13. Edinboro $L E$, Karnes $H T$ : Determination of aflatoxin $B 1$ in sidestream cigarette smoke by immunoaffinity column extraction coupled with liquid chromatography/mass spectrometry. J Chromatogr A 2005, 1083:127-132
14. Barnes RL, Glantz SA: Endotoxins in tobacco smoke: shifting tobacco industry positions. Nicotine Tob Res 2007, 9(10):995-1004.

15. Papavassiliou J, Piperakis G, Marcelou-Kinti U: Mycological flora of cigarettes. Mycopathology Mycology Applied 1971, 44(2):117-120.

16. Zhao M, Wang B, Li F, Qiu L, Li F, Wang S, Cui J: Analysis of bacterial communities on aging flue-cured tobacco leaves by $16 \mathrm{~S}$ rDNA PCR-DGGE technology. Appl Microbiol Biotechnol 2007, 73(6):1435-1440.

17. Rooney AP, Swezey JL, Wicklow DT, McAtee MJ: Bacterial species diversity in cigarettes linked to an investigation of severe pneumonitis in U.S. military personnel deployed in Operation Iraqi Freedom. Curr Microbiol 2005, 51(1):46-52

18. Pauly JL, Waight JD, Paszkiewicz GM: Tobacco flakes on cigarette filters grow bacteria: a potential health risk to the smoker? Tob Control 2008 17(1):49-52

19. Schick S, Glantz S: Philip Morris toxicological experiments with fresh sidestream smoke: more toxic than mainstream smoke. Tob Control 2005, 14:396-404.

20. Kulkarni GS, Nadkarni PP, Cerreta JM, Ma S, Cantor JO: Short-term cigarette smoke exposure potentiates endotoxin-induced pulmonary inflammation. Exp Lung Res 2007, 33(1):1-13.

21. Schwartz DA, Thorne PS, Yagla SJ, Burmeister LF, Olenchock SA, Watt JL, Quinn TJ: The role of endotoxin in grain dust-induced lung disease. Am J Respir Crit Care Med 1995, 152:603-608.

22. Heldal KK, Halstensen AS, Thorn J, Eduard W, Halstensen TS: Airway inflammation in waste handlers exposed to bioaerosols assessed by induced sputum. Eur Respir J 2003, 21:641-645.

doi:10.1186/1617-9625-10-13

Cite this article as: Larsson et al:: Microbiological components in mainstream and sidestream cigarette smoke. Tobacco Induced Diseases 2012 10:13

\section{Submit your next manuscript to BioMed Central and take full advantage of:}

- Convenient online submission

- Thorough peer review

- No space constraints or color figure charges

- Immediate publication on acceptance

- Inclusion in PubMed, CAS, Scopus and Google Scholar

- Research which is freely available for redistribution 